\title{
Deirdre McKay, An Archipelago of Care: Filipino Migrants and Global Networks
}

\author{
Bloomington, Indiana University Press, 2016
}

Labour migration has been part of the Philippine government's economic policy since the 1970s. What was supposed to be a temporary solution at that time has become a survival strategy and one of the country's economic pillars today. The global increase in dual-income households and ageing populations in the past decades have contributed to the growing demand for reproductive labour, or care work. Reproductive labour is work associated with care and domestic work that sustains the lives of family members. Reproductive labour is both physically and emotionally demanding; lonely; prone to exploitative practices; and usually remunerated inadequately (3); and as a result, it is considered less desirable than other forms of employment. Meanwhile, Filipino migrant workers have created a niche in the global labour market and are recognized as people who deliver high quality effective care and whose skills are in demand in the global job market despite lacking the formal papers and right to work (2). This has created circumstances in which care work performed by migrants especially from the Global South is increasing, and as such creates a reality in which care workers and their skills are not easily substituted by the local population (2).

The title of Deirdre McKay's book, An Archipelago of Care: Filipino Migrants and Global Networks denotes both the physical and political geography of the Philippines, i.e. an archipelago, and a recognition of the global scale of Filipino migrants all over the world and the archipelagic nature of their network. It also establishes the topic of care, which is accentuated by the abstract artwork on the cover, which shows a mother holding her two children. The title and the cover art indicate that the book is about the correlation between care work and global networks through the stories of Filipino migrants.

However, the book is much more nuanced than that. It offers rich descriptive and intimate ethnographic accounts focusing on two irregular migrants, Labanet and Biag. McKay followed and documented Labanet and Biag's sojourn in the United Kingdom and the Philippines, meeting their migrant friends in London who eventually became participants in her research. While the book is centred around Labanet and Biag's story, it presents information and themes from McKay's five years of ethnographic fieldwork (2009-2014) and formal interviews with sixty-one Filipino migrants.

Most research and books about the Filipino diaspora focus on the economic and social consequences of the migration process for the host and origin countries. The literature has focused on the migration process, globalization and capitalism, the agency of migrants, migration and repatriation policies and their implementation. There is also a significant amount of literature on working conditions. What all the existing literature on Filipino migration has in common is the Filipinos' capacity for hard work and care, which is reinforced in McKay's ethnography. 
McKay introduces the concept of the "migrant ethic of care" (25), a notion which places migrant reproductive labourers as somewhat better equipped to provide care for strangers than their non-migrant counterparts. Her research demonstrates how this "migrant ethic of care" originated in culture: "cultural concepts, practices, and spaces created the Filipino [migrants'] capacity and reputation for care" (2). McKay argues that this particular brand of care that the Filipino migrants provide, despite lacking the formal right to work, is generated and sustained through migrants' transnational care networks. Interaction with these transnational networks carry either a positive or negative "affect" which is then articulated and transformed into the migrants' sense of self and the care they provide.

McKay adds another layer to the existing literature on Filipino migrants' reputation for care by drawing on the concept of "affect". She argues that care is generated through the "affective flows and underlying ethics and norms channeling affect [across several] nodes" (161). The nodes she refers to connect spaces in the United Kingdom, the Philippines, and other places in the world through migrant networks. Affect manifests physically and digitally across the migrants' networks which then translates into effective care despite the precarity of the migrants' situation. McKay defines affect as the "primal energy flowing between people and attaching us to each other, our ideas, our institutions, and our relationships ... [it underpins] people's emotions, behaviors, and actions (5)." Nevertheless, she acknowledges that affect is a concept that is hard to grasp as it is not easily contextualized.

To further drive the point of the particular brand of care that Filipino migrants provide, and how these skills are not easily substituted, McKay highlights Filipino migrants' clear sense of purpose and their optimism, which stands out against the growing number of their disenfranchised local counterparts in the Global North. She draws from Henrietta Moore's "still life" and Saskia Sassen's "political economy of expulsion" to capture the background in which Filipino migrants' optimism and skills for effective care stand out against the "affective paralysis in which, with no pleasurable future or security on the horizon, people withdraw, defer, and disconnect, expressing only self-interest and apathy" (9).

Migrants' emotions also underpin McKay's research, and are what makes her book stand out amongst the abundant literature on the Filipino diaspora. She acknowledges the migrant workers' individual and collective emotional interdependence. Her book also highlights the transnationality of migrants' coping strategies, articulated through their ever-changing global networks, which underscores the complexity of and questions traditional notions of proximity and distance relating to "being cared about" and "being cared for".

The book focuses on the experiences and stories of Kankanaey Filipino migrant care workers in London. The Kankanaey are a group of indigenous people in the Northern Philippines with a rich vibrant regional culture (4). In the course of McKay's five years (2009 to 2014) of ethnographic research, more than half of her sixty-one 
participants were and would be irregular migrants, working without authorization and papers $(3,15)$.

Through her long-term ethnographic approach, McKay was able to track significant changes in migrants' global networks, their feelings, and their stories (16). Her approach also allowed her to follow some of her participants from London back to the Philippines. She used data gathered both in the United Kingdom and the Philippines through participant observation, interview transcripts, text from online chats, e-mail exchanges, media reports, government documents, and Facebook posts in groups and profiles, to develop and support the argument and themes in the book (16). She also conducted follow-up interviews and correspondence with them over the five years of her ethnographic research.

McKay's monograph documents the sojourn of Filipino migrants with Kankanaey roots, who despite the precarity and vulnerability of their situation are able to care for strangers effectively and live their lives with optimism. The book demonstrates the complex relations and of these migrants with each other, and their networks from the UK, the Philippines, and from other parts of the world. It narrates the intricate details of the migrants' wide and far-reaching global networks and how the flow of affect in these networks transforms the work they deliver as well as the landscape of the global.

McKay skilfully structures the book in a manner that takes the readers in as soon as a glimpse of her argument is offered in the first few sentences. She gives an overview of the book - what it is about, what are the themes, what it contributes to the field - in the introduction, yet she leaves enough intrigue to keep the reader turning the pages. More importantly, the structure of the book itself helps form and deepen the reader's understanding of her argument, as well as connect with the experiences of the participants characterized in the book. McKay effectively intertwines engaging storytelling and research writing.

Notwithstanding McKay's rich ethnographic data, no demographic ratio of gender is mentioned in the book. Several male characters are mentioned, including one of the main characters, Biag. However, it is implied that the majority of the participants in the study were female. This corresponds to previous research studies on the Filipino diaspora, and the statistics of the Philippine government and migration NGOs, that reproductive care work has been highly feminized. McKay also sheds some light on the LGBT+ members of the migrant community, through the inclusion of a few anecdotal experiences of lesbian Filipino migrants within Labanet's social network.

The information presented in the book also enriches the literature on netizenship, subversive citizenship, and prosthetic citizenship. Such themes have usually been studied separately from the literature on reproductive work and the Filipino diaspora. It demonstrates how the frustration of formal and local citizens with migration regulations and the inequalities they produce translate into support for irregular migrants; subversive citizens refuse to police the borders themselves, employ 
and/or help irregular migrants, and recognize migrant contributions to British society (85-87). Subversive citizenship helps sustain irregular migration and care work despite the attempts of the government to control irregular migration flows.

Filipino migrants still maintain and participate in active citizenship in both the UK and the Philippines. The UK sojourns of Filipino migrants fund their family's commitments and projects back in the Philippines, and therefore they actively participate in politics in the Philippines online as netizens (84). This participation carries an affective charge that sustains their daily life in the UK. Irregular migrants also practice prosthetic citizenship, acting as if they are already good UK citizens, both physically and digitally (92). They recognize the importance of image and their portrayal of themselves in sustaining their irregular status. They dress, shop, go to places, move and act like formal citizens. Social media are used to publicly archive how they have become or are on their way to becoming good formal UK citizens, despite being irregular (92).

The importance of digital life via Facebook, email and Skype is also emphasized. An entire chapter is dedicated to how migrant networks are continuously reshaped on Facebook. Migrants stay connected with each other, with their families, and with their employers, online. McKay points out how affect also flows digitally. A Facebook post, comment, like, or even the absence of tags, likes, and comments carry affective charges that are felt by the migrants. More than strengthening her argument on affective flows and networks, McKay also demonstrates how Facebook serves as a platform for netizenship as well as subversive and prosthetic citizenship (51-69).

The affect flowing in migrants' global networks show how migrants, despite their precarious and vulnerable situation, are able to provide effective care. Affect flows everywhere, in Church, in the home, on social media, in gifts, at events, in boxes sent home, in plans for the future, in politics. These affective nodes in their networks generate the eponymous "archipelago of care" in which migrants create their sense of self and also shape the structure of the global political economy. With the wealth of ethnographic data she presents, McKay reveals the power of "affect" to reconfigure the global and how it plays a major role in the manipulation of the identities, markets and values comprising globalization $(7,13)$.

McKay challenges the prevalent notion that labour migrants want to acquire citizenship, stay, and retire in the welfare-state host country. McKay includes a chapter called "Back Home" that details her participants' plans to go back and retire in the Philippines. Even those who have acquired formal citizenship want to go back home when they retire. McKay also reveals migrants' agency in actively choosing to participate in the informal economy of reproductive care work. McKay's ethnography includes cases of students with student visas eventually giving up on attending classes and instead doing full-time informal care work and instances in which Filipino migrants choose to remain irregular despite the precarity of the situation because of the bigger payout. For the migrants, tenure and access to social security and benefits in the UK do not necessarily matter; their plans "Back Home" are what really 
matter. Even these plans also carry affective charges that translate into the migrants' sense of themselves as well as their ability to provide care.

Archipelago of Care is a stimulating contribution to the literature on reproductive labour. London serves as a good example of a Western, democratic, and urbanized capital in Europe. Meanwhile, despite the participants in McKay's study drawing from Kankanaey culture in explaining their ability and capacity to provide care, the concepts they reveal have their respective counterparts in the Filipino national culture. Hence, McKay's argument and ethnographic data may serve as a model of the correlation between reproductive care work and global networks even for Filipinos without Kankanaey roots and in other Western democratic countries.

The book presents a model that will be interesting for scholars of the Filipino diaspora and migration studies in general. Nonetheless, it remains to be seen if such models, and if such ethnography, will yield the same results in the Arab region or in countries with more traditional/conservative or more oppressive regimes where there are more intense exploitative working conditions, surveillance, policing, limitations on social interaction and gatherings, etc. More importantly, such research would hold importance for Filipinos, and the Philippine government, because according to the statistics by the Philippine Overseas Employment Agency - the government agency in charge of regulating labour migration - the Philippines have been sending the largest number of formal reproductive labourers to the Middle East over the last five years.

McKay's book suggests the limits of state and formal market mechanisms. The growing informalisation of reproductive care work shows that the need is only supplied by migrants, for a myriad of reasons, and it is not easily replaced and substituted. The state's refusal to recognize this need will just continue to propagate the informal economy of reproductive labour. In an increasingly globalized and capitalized world, McKay's "migrant ethic of care" shows how reproductive labour is resisting complete and ultimate commodification. 